ORIGINAL ARTICLE

\title{
Individualization of selection and training of female athletes in speed-power athletics from the perspective of gender identity
}

\author{
Eugeny Vrublevskiy ${ }^{1,2 \mathrm{ADE}}$, Anatoly Skrypko ${ }^{3 \mathrm{ABDE}}$, Ryszard Asienkiewicz ${ }^{2 \mathrm{ABCDE}}$ \\ ${ }^{1}$ Francisk Skorina Gomel State University, Belarus \\ ${ }^{2}$ University of Zielona Góra, Poland \\ ${ }^{3}$ State University of Applied Sciences in Kalisz, Poland
}

Authors' Contribution: A - Study design; B - Data collection; C - Statistical analysis; D - Manuscript Preparation; E - Funds Collection

\begin{abstract}
Purpose: $\quad$ To develop and justify the criteria for morphogenetic markers of speed-power abilities of athletes and the main directions of individualization of the process of their preparation, taking into account the characteristics of the female body.

Material: $\quad$ Using the "2D: 4D" determination methodology, finger proportions were analysed for 126 qualified athletes specializing in speed-strength types (sprinting and hurdling, jumping, shot-putting) of different ages (from 17 to 25 years old). For 13 weeks, eight qualified short-distance student runners were regularly tested using computer strain gauge equipment: 5 masculine and 3 feminine types. The tensodynamograms of the manifestation of the strength of muscle groups carrying the main load in the structure of the sprint run were recorded and processed.

Results: It was found that $78 \%$ of the examined athletes observed finger proportions close to the "male" proportions. This may indicate their certain masculinization. The technique used for this can be an informative and simple marker to predict a genetic predisposition to the ability of effective performance of speed-power work. It was determined that the same amount of power load causes masculine athletes, runners for short distances, a more significant deployment of long-term adaptation restructuring of masculine athletes, runners for short distances, compared with athletes of a different gender identity.

Conclusions: Criteria for the prognostic assessment of speed-power abilities of athletes based on simple biological markers for testing and identification, like finger proportions (2D: 4D), have been developed. For athletes of high qualification who have a gender identity similar to men and a masculine somatotype, it is possible to use adapted male techniques for training.

Keywords: athletics, athletes, speed-strength indicators, individualization, gender identity, morphogenetic markers, selection.
\end{abstract}

\section{Introduction}

In recent decades, the development of highperformance sports has been accompanied by an increasingly active involvement of female representatives in it. However, at present, the training process for women is often based on the generally accepted methodology for men, where the dominant direction is to increase the amount of training loads [1-4]. In the system of sports training, in addition to general provisions, there are features that are characteristic only for women. These features lead to differences in the course of adaptation processes in the female body. These processes are earlier biological maturation, significant fluctuations in the level of performance in accordance with the nature phases of the ovarian-menstrual cycle (OMC), psychological characteristics, social factors, etc. [5-8].

When discussing many unresolved issues of women's sports, the comparison of all parameters among athletes in most of the works of the past years was carried out in comparison with the "standard" (feminine) woman. At the same time, it is doubtful that a feminine woman can push the core far, jump high or quickly run 100 meters. In elite sports (with the rare exception), only a masculine

(c) Eugeny Vrublevskiy, Anatoly Skrypko, Ryszard Asienkiewicz, 2020 doi:10.15561/20755279.2020.0405 woman who is close in physiological and psychological parameters to male athletes can "survive". Meanwhile, doctors have data on the presence in the population of women with a high content of male sex hormones in the body [9-11]. It is the latter that provide them with similarity with men in morphological characteristics and give an advantage in the development of speed-power indicators. First of all, this is an athletic (masculine) somatotype, characterized by a reduced fat content and a high content of muscle mass.

So, back in the 70 s of the last century Radzievsky and his co-workers $[12,13]$ observed a group of athletes with a well-developed shoulder girdle, a relatively narrow pelvis, and weakly developed mammary glands. These athletes at the beginning of their sports activities (with delayed puberty) achieved success and easily cope with stress due to the presence of a large number of androgens (male sex hormones) in the body, which, being the standard of anabolic hormones, increase performance and promote the development of muscle mass. In the future, with the irrational construction of the training process and not taking into account the biological characteristics of the female body, excessive muscle loads and emotional factors can cause changes in the system of "hypothalamuspituitary-adrenal gland-ovary" in this group of athletes. 
It has been shown [14-17] that intense physical activity causes changes in the sequence of manifestation of secondary sexual characteristics in adolescent girls, causing some androgenization of the body.

In recent years, many scientists have expressed the opinion, that among athletes of all age groups (girls, girls, women) signs that indicate greater masculinity are expressed more distinctly than amongst women who do not engage in sports [10, 18]. First of all, these are morphological signs: somatotype (shoulder width is greater than the width of the pelvis, a change in the ratio between fat and muscle tissue in favor of the latter), hirsutism (male type of hair growth, i.e. the appearance of hair in areas not characteristic of a woman), hypoplasia (underdevelopment) of the breast, etc. [1, 19-21]. There are also functional disorders associated with a change in the menstrual cycle $[18,22]$. All this may indicate an increased content of male hormones in the body of athletes.

Therefore, there were some disagreements between the authors regarding the dynamics of the manifestation of motor abilities and performance in competitions during one or another phase of OMC. These may have occurred due to the fact that the researchers did not take into account the severity of masculinity and femininity in athletes.

Meanwhile, as shown in a number of works, the severity of masculinity and femininity significantly changes the overall picture, which was revealed both among children [23, 24] and adults [25-27]. A study in the United States showed the highest masculinity scores for black women, followed by Hispanics latinas and then white women [28].

Manning with his team [29-31], obtained the proportion of fingers which in the scientific world was defined as "2D: 4D". That is, the aspect ratio of the index (second) finger and ring (fourth). The result is as follows: for most men, the ring finger is slightly longer than the index finger (male type of hand), the proportion of 2D: 4D ranges from 0.96-0.99.

For women, the proportion is "inverted" (vice versa) and ranges from 0.99 to 1.1 (female type of hand). In this case, the index finger is usually longer than the ring finger. The middle variant is observed in both sexes, but is more common in women (Fig. 2).
The authors note that a different proportion of the 2D: 4D proportion can be associated with a predisposition to the development of certain diseases and sexual orientation $[29,33,34]$. In addition, various abilities, including motor abilities, were indicated. Finger proportions, scientists say $[19,35]$, are developed very early in the process of prenatal development, when the embryo is about three months old. The length of the second finger is affected by the "female" sex hormone estrogen, and the fourth by the "male" sex hormone testosterone.

There is little consideration of ideas about masculinity and femininity as sexual types in the literature. Therefore, the need to take them into account when judging certain differences between athletes and athletes is not sufficiently shown. In addition, the urgent issue remains the selection in speed-strength types of athletics of women close to men in morphological and psychophysical indicators, and the development of criteria for this selection.

Hypothesis. The morphogenetic markers are easy to test and identify. It was assumed that the identification of these markers can serve for rapid diagnosis of the individual characteristics of an athlete's genetic potential when selecting athletes with speed-strength types. This will also help with determining means and methods of training effects in athletes with determinate signs of masculinity.

Purpose: to develop and justify the criteria for morphogenetic markers of speed-power abilities of athletes and the main directions of individualization of the process of their preparation, taking into account the characteristics of the female body.

\section{Materials and methods}

Participants.

Using the "2D: 4D" determination methodology, we analysed finger proportions of 126 qualified athletes specializing in speed-power types (sprinting and hurdling, jumping, shop-putting) of different ages (from 17 to 25 years old). During the observations, eight qualified female short-distance runners were regularly tested: 5 masculine types with "male" finger proportions and 3 feminine ones with "female" finger proportions.

Research design.

The study was conducted in two stages. The main

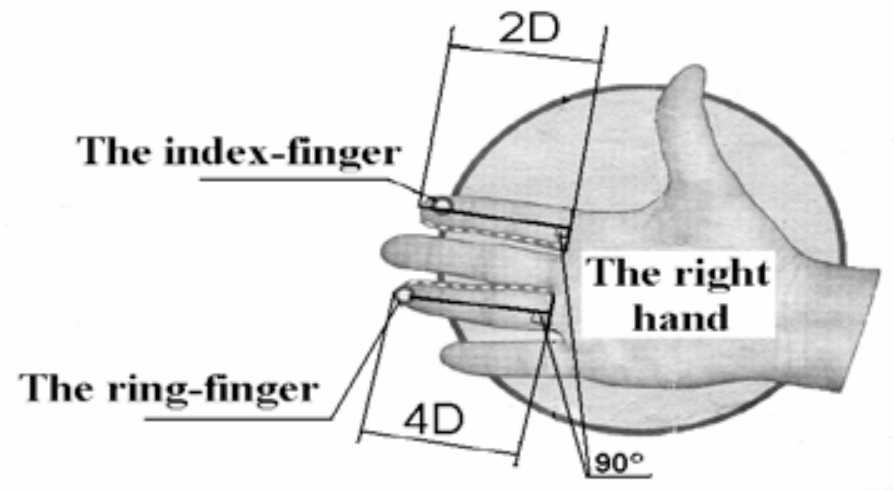

Figure 1. Methodology of measuring finger proportions [32] 


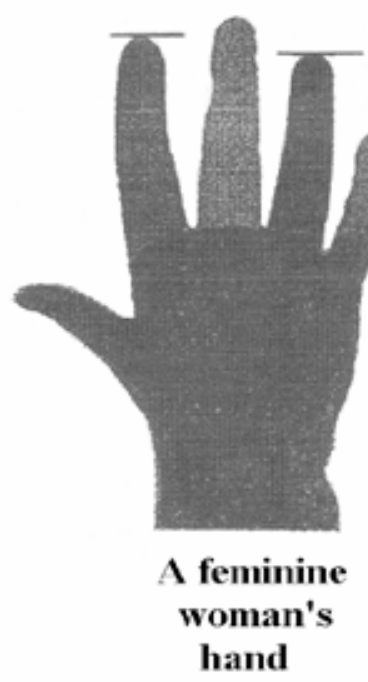

Figure 2. Finger proportions (2D: 4D) for women and men

direction of the experiment was the determination of the finger proportions of the length of the second (2D) and fourth (4D) fingers, called the "Manning distribution". It was determined by the author's technique [29-32] (Fig. $1)$.

To study the manifestations of masculinization of the psyche of an individual, the data of athletes were tested. It was done according to the standardized method of "masculinity-femininity" of Bem [36] with the simultaneous filling out of a questionnaire. The questions primarily focused on the orientation of the training taking into account the individual specifics of the body's biorhythmic.

The analysis of training loads in men and women specializing in sprinting and hurdling was carried out. Both the total annual volumes of training tools and the main trends in their distribution over the stages of the annual training cycle were determined.

At the second stage of the study, the dynamics of indicators of special strength training of athletes of different gender identities were determined. It was done during the performance of volumetric (concentrated) power load and in the subsequent period of its reduction. To do this, eight qualified female short-distance runners were regularly tested for 13 weeks: 5 masculine types with "male" finger proportions and 3 feminine ones with "female" finger proportions.

For instrumental control of the strength and speedstrength capabilities of the muscles of the lower extremities of athletes, the method of computer tensodynamography was used. This technique allowed us to assess the level of special strength training based on a set of specific data. These data characterized a person's ability to manifest "explosive forces", which cannot be measured directly. $[37,38]$.

The tensodynamograms of the manifestation of the strength of muscle groups bearing the main load in the structure of sprinting - muscles, extensors of the leg (EL) in the knee and hip joints and plantar flexors of the foot (PFF) were recorded and processed. In the isometric mode, the installation was given to show the maximum (absolute) arbitrary force in the explosive isometric mode (for the rapid achievement of maximum force in the shortest period of time).

Based on the obtained tensi-dynamometric curves, the maximum isometric muscle strength (Fmax) was determined, manifested in the described movement, and the time during which the maximum force (tmax) was achieved. The differential index (gradient) of explosive force $(\mathrm{J})$ was calculated, which characterizes the rate of increase of the force to the maximum and numerically equal to $\mathrm{J}=$ Fmax / tmax.

The frequency of testing was two times a month, and at separate stages three times a month. For the credibility sake, the data was correlated with the phases of the OMC of each athlete.

Statistical Analysis. The arithmetic means of the indicators (M), standard deviation (s) and standard error (m) were determined. The significance of differences in the average values of independent samples evaluated by parametric methods applying Student's t-test. The differences between the values of indicators with a level of $p<0.05$ were considered significant.

\section{Results}

Among $78 \%$ of the examined athletes, the finger proportion close to the "male" $(0.98-0.99)$ was observed. This may indicate a certain masculinization. The technique used for this can be an informative and simple marker, according to which it is possible to predict a genetic predisposition of effective performance of highspeed power work of maximum power. Testing results by the standardized method of "masculinity-femininity" of S. Bem also showed that the tested group of athletes had bigger $(63 \%)$ masculinization of their psyche.

The data from the questionnaires of athletes was obtained, which indicate that in $58 \%$ of athletes' fathers or mothers, to one extent or another, went in for sports. The athletes who didn't have male finger proportions also achieved high athletic performance. However, they 
probably needed to put more effort into training to achieve this level.

Analysis of training loads of athletes specializing in sprinting and hurdling showed, that masculine athletes, the percentage of which was $82 \%$, perform a statistically significant $(p<0.05)$ larger amount of work in the annual cycle. The identity of both the annual volumes of training aids and the main trends in their distribution by mesocycles in male runners and masculine female runners was revealed (small differences were noted only in the volume and distribution of the training load of glycolytic orientation).

The common mechanisms of adaptation to various environmental influences and the predisposition of women to perform heavy physical exertion allow them to carry out a similar, and in some cases, more significant amount of training work compared to men. Therefore, the general methodology for constructing training is acceptable. However, it should be done taking into account the peculiarities of the female body when planning the training in accordance with the individual dynamics of performance over the phases of the OMC.

The results of the survey showed that masculine type of athletes noted a slight decrease in performance (according to subjective sensations) in various phases of the OMC. In this group, the percentage of women $(28.2 \%)$ who tolerate training loads in the premenstrual and menstrual phases of the OMC is quite high. Meanwhile, $23.6 \%$ of respondents believe that it makes no difference to them at what phase of the cycle the training load is performed.

The analysis showed (Fig. 3) that during the performance of the volumetric power load (the first six weeks), all athletes significantly decreased $(p<0.05)$ the explosive strength of the leg extensor muscles $(\mathrm{PH})$ and plantar foot flexors (PSS). Also, the deteriorating results in jumping from leg to leg for $100 \mathrm{~m}$ with fixing the execution time were decreased. Moreover, a significant decrease in the recorded indicators for the same load was

\section{Group A}

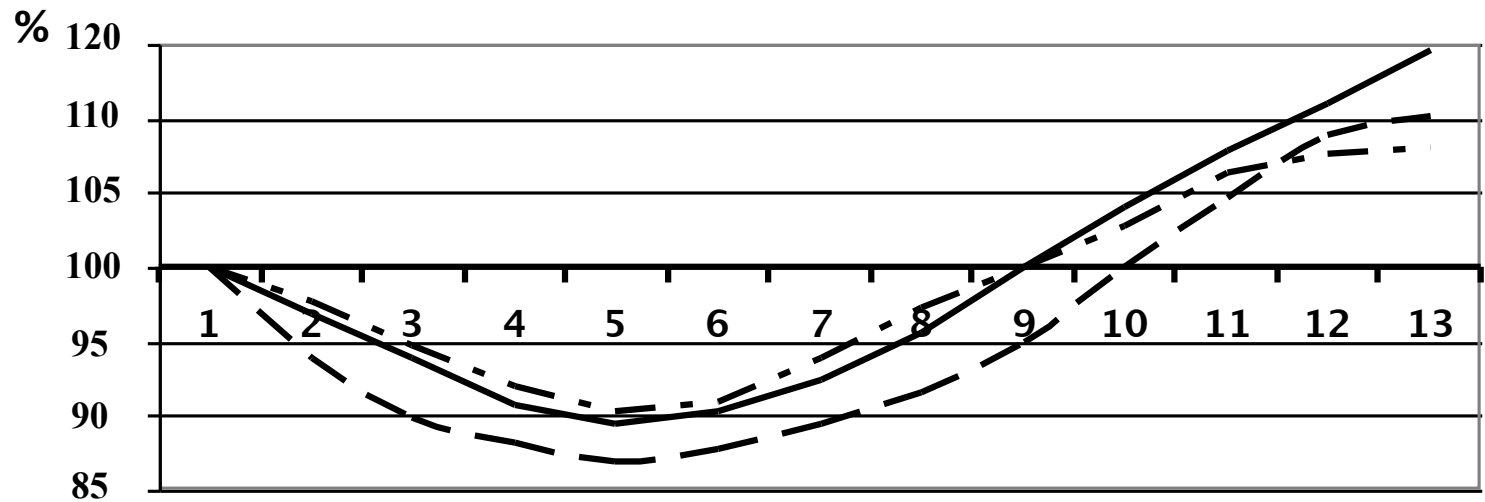

the explosive force of LE

weeks

- the explosive force of FPF

Group B

$\%$

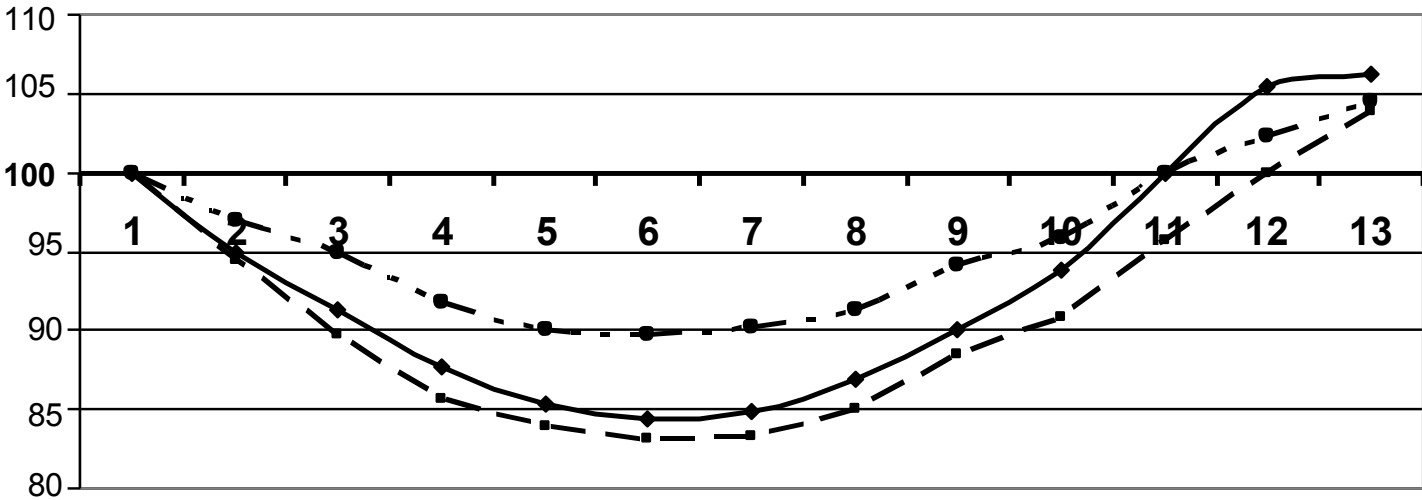

$\longrightarrow$ the explosive force of LE

- - - the explosive force of FPF

weeks

-*- - 100-metre from-leg-to-leg jumping

Figure 3. Dynamics of speed-strength indicators in short-distance runners of different gender identities during the observation period 
observed among the athletes of group B. On the 5th week of observations, when the training load was the largest, the explosive strength of the extensor muscles of the legs of the athletes of group A decreased, on average, by $10.6 \%$. For the group $\mathrm{B}$ it decreased by $15.6 \%$; the power of muscles of plantar flexors of the foot, decreased respectively, by 13.0 and $16.3 \%$. The results in jumping from leg to leg temporarily decreased, respectively, on average, by 9.8 and $10.3 \%$.

After reducing the amount of the training load, the athletes increase indicators characterizing special strength preparedness. This was due to the manifestation of the delayed cumulative effect of the previous work of speedstrength nature. At the last (13th) week of observations, the explosive strength of the extensor muscles of the leg increased, compared with the initial level, in group A, on average, by $16.6 \%$, and in group B - by $6.2 \%$, explosive muscle strength plantar flexors of the foot, by 10.1 and $4.0 \%$ respectively.

The results of jumping $100 \mathrm{~m}$ from leg to leg increased, by 8.6 and $4.5 \%$ respectively. The noted changes in the athletes of group A are significant ( $p$ $<0.05)$. The same load with the feminine type athletes can cause a more significant deployment of long-term adaptive rearrangements. In addition, upon completion of the observation, group A athletes, in comparison with background indicators, recorded a higher step module (the ratio of the length of the running step to the length of the leg)

All of the above indicates that the essence of the adaptation process consists not only of increasing the motor potential of an individual, but also of the everincreasing ability, use the modes of muscle work to solve a specific motor task. This can be accomplished to a greater extent by motor-gifted runners with proportions of fingers close to masculine.

\section{Discussion}

Recently the biologists have been distinguishing several levels of human sexual organization [39]: genetic sex (a specific set of genes); gonadal sex (endocrine glands); morphological sex (external and internal genital organs); cerebral sex (brain differentiation under the influence of testosterone). It was revealed [34] that the brain carries in itself the possibility of programming behavior in both male and female types. Male and female sex hormones are produced by both male and female organisms, and hormonal masculinity or femininity are determined by the predominance of one or the other [9]. The question is, where do the masculine women, which are the most "valuable" for the speed-power types of athletics, come from?

Some authors $[13,20,40,41]$ consider physical activity, which activates the adrenal cortex and increases the release of male sex hormones (androgens) to be primary. Normally, they are excreted in small amounts by the adrenal cortex, while physical activity is a stress factor for the body. According to Selye [42], the adrenal glands play a major role in adapting the body to a stressful situation. Moreover, the latter leads to a decrease in the synthesis of female hormones of estrogen and an increase in male hormones - androgens. This option allows us to say that any stressor triggers a similar mechanism leading to "hyperandrogenism syndrome" $[10,18,43,44]$. This, in their opinion, is the reason for the muscularization of female athletes, including the formation of a male somatotype.

Other researchers argue, that this is the result of the selection of girls of male somatotype in women' sports $[10,19,45,46]$. As a matter of fact, these researchers distinguish the composition of skeletal muscle fibers [9], the masculine type of dermatoglyphics [47] and some psychological features as markers [36]. However, due to the lack of development, invasiveness and complexity of determination, these criteria have yet to found wide practical application.

Interestingly, the methodology of "2D: 4D" was also used by other specialists [46, 48-52]. Kamińska and Szymańska-Parkieta [53] studied a large group of schoolgirls of 13 years old and found that in physically more developed girls, the proportions of the fingers were close to male.

There is an opinion $[35,54]$ that sexual differentiation of the brain is still taking place in utero, the violation of which with increased content of male sex hormones leads to the fact that the female embryo can "defeminize". This, in its turn, manifests itself in the masculinization of female behavior (sexual dimorphism of the psyche) [14].

Masculinization of the brain of female fetuses can occur under the influence of male sex hormones, the use of certain drugs (including birth control) and stress. The observations and experiments of Rosenfield [55] proved that the observed three-year-old girls whose developing in the womb was in an environment saturated with testosterone, not only behave like boys, but also play with them more willingly. They also find toys for girls not interesting for themselves. This feature comes forward in women's sports and subsequently forms the basis of athletic success.

The increased content of androgens in the body of the girl leads to the formation of a male somatotype. It is characterized by an increase in growth and shoulder width with a decrease in the width of the pelvis, decrease of body fat and increased muscle mass.

The results of the study by Soboleva [10] show that the average body weight of newborn girls, mothers of who are women involved in sports is mainly higher than of the not involved ones. According to the author, this fact may indirectly indicate that in athletes the intrauterine development of the female fetus occurs in conditions of the increased androgen content. This feature begins at the prenatal period followed by its activization during puberty [26]. Masculinization of the girl's body is an important prerequisite for going into sports while being a child with subsequent development in adulthood [10, 31, 52].

According to the data of Kliorin and Chtetsov [56], the muscular somatotype in children is already determined from birth. In the population among girls of 
8-9 years old it is registered that there is $7.7 \%$ of such somatotype, among $13-14$ years old it is $6.8 \%$. Thus, it is important to emphasize that among the female population the representation of the muscle constitution is relatively small - only $7-8 \%$. It can be assumed that the small number of representatives of the muscular somatotype of the female population is concentrated in the women's sports.

In our opinion, there is no point in arguing about what determines the hyperandrogenism of masculine athletes: selection or the impact of a training load. As with many other issues, the issue should not be considered from an "either-or" perspective. Both one and the other factors matter, and it is almost impossible to separate them from each other. Apparently, when playing sports, there is an aggravation of what is "given" to a person from birth.

Thus, when studying the differences between men and women involved in sports, it should be borne in mind that their traditional comparison does not correspond to the existing reality. The latter consists in the presence of sexual types, and not just biological sexes. Therefore, it is more promising to study the similarities and differences not between biological sexes, but the sexual types of men and women, taking into account masculinity and femininity.

Meanwhile, the problem of sexual dimorphism should be considered more broadly. So, according to the evolutionary theory of sex by the famous domestic biologist Geodakyan [57], the feasibility of having two sexes consists in their specialization in two main alternative directions of the evolutionary process: progressive and conservative. The male sex implements a "progressive" trend, and the female - "conservative". The flow of information from the environment is first perceived by the male gender. Only after sifting out steady shifts from temporary and random, does the genetic information get into the "information core" of the female population. Therefore, new tasks that are solved for the first time, subject to the maximum requirements for novelty and minimum to perfection, are best solved by men. Familiar tasks (minimum of novelty, maximum perfection), in their term, are best solved by women.

With regard to sports, this may mean that all valuable findings observed by men in the training methodology and the technique of sport types, women retain and improve. In addition, Geodakyan [57] formulated a rule: if by any sign there is a sexual dimorphism, then this sign evolves from the male form to the female one.
How to correlate this with sports activities? A professor at Peking University Lee Nyang [58] put forward a hypothesis confirming, in some cases (with a positive test for doping), the non-involvement of athletes involved in speed-strength sports in the use of prohibited substances. According to the results of his research, during the period of the largest power loads, there was observed the increased production of male hormones, which can be recorded as doping. Aware of the importance of this fact, the professor sent the results of his laboratory research to the International Olympic Committee.

This work does not claim to solve the whole problem of sexual dimorphism in sports. Its purpose is to draw attention to issues requiring extensive and comprehensive research.

\section{Conclusions}

1. The girls of the muscle (male) somatotype are concentrated in the speed-strength types of athletics, as a result of the selection. This is due to the fact, that this somatotype has all the morphofunctional and psychoemotional prerequisites for heavy and daily physical exercise for many years.

2. It becomes obvious that a simple comparison of male and female groups in many cases is unpromising. In fact, the identification of gender differences should be based not on morphological characteristics (according to the genetic sex), but taking into account the hormonal sex, which determines masculinity and femininity.

3. The study allows us to formulate criteria for the prognostic assessment of speed-power abilities based on such simple biological markers for testing and identification as finger proportions (2D: 4D). The latter can be used at the stages of early orientation and initial of selection hereditarily determined signs of masculinity in athletes.

4. Knowing the specific predisposition of even qualified athletes will allow the trainer to determine the range of opportunities, the nature and methods of pedagogical influences more clearly.

5. Violation of the rhythmic functioning of $\mathrm{OMC}$, often observed in masculine athletes, is a kind of "price" for the body to achieve a high level of adaptation to intense training and competitive loads.

\section{Conflict of interest}

The authors declare no conflict of interest. 


\section{References}

1. Socha T. Methodology to improve educational systems of women's sports training in aspect of sexual dimorphism. [dissertation]. St. Petersburg; 2002. (in Russian)

2. Issurin VB. Training of athletes of the XXI century. Scientific basis and the construction of training. Moscow: Sport; 2016. (in Russian)

3. Platonov VN. The system of training athletes in the Olympic sport. General theory and its practical applications. Kyiv: Olympic literature; 2015. (in Russian)

4. Pound RW. Women in Sport. XIII Olympic Congress. Lausanne, Switzerland: International Olympic Committee; 2009.

5. Kostyuchenko VF, Vrublevskiy EP, Kozhedub MS. Methods of individualized training of athletes in the annual cycle, specializing in sprinting. Scientific notes of the University. P.F. Lesgaft. 2017; 10 (152): 115-121. (in Russian)

6. Wajewski A. Poznawcze $i$ metodyczne problemy sportu kobiet [Cognitive and methodical problems of women's sport].Warszawa: AWF; 2009. (in Polish)

7. Shakhlina LA-G. Biomedical basis for women's sports training. Kiev: Naukova Dumka; 2001. (in Russian)

8. Hecht SS, Arendt E. Training the Female Athlete. In: Mountjoy ML, editor. Handbook of Sports Medicine and Science, Hoboken, NJ, USA: John Wiley \& Sons, Inc.; 2014, P. 1-8. https://doi.org/10.1002/9781118862254.ch1

9. Money J. Sexual dimorphism and homosexual gender. Psychological Bulletin. 1970; 74: 425- 440. https://doi.org/10.1037/h0033067

10.Soboleva TS, Sobolev DV. Sporting success among women with different set of sex characteristics. Medicine and Physical Education:ScienceandPractice, 2020;2(5):76-81.(inRussian) https://doi.org/10.20310/2658-7688-2020-2-1(5)-76-81

11. Williams CA, Oliver JL, Lloyd RS. Talent development. London; New York: Routledge; 2014.

12.Radzievsky AR, Loza GA, Gashumov AM, Radzievsky PA. Anatomical and physiological characteristics of the female body. Women's sports: collection of proceedings; 1975: 1034. (in Russian)

13.Levenets SA. Features of the formation of the function of the reproductive system of adolescent girls who regularly engage in sports. [dissertation]. Kharkov; 1980. (in Russian)

14.Collaer M, Hines M. Human behavioral sex differences: A role for gonadal hormones during early development? Psychological Bulletin, 1995; 118: 55-107. https://doi.org/10.1037/0033-2909.118.1.55

15. Whalen RE. Brain mechanisms controlling sexual behavior. Beach F.A. (ed.) Sexuality in Four Perspectives. Baltimore, London; 1977. P. 215-246.

16.Anan'ev BG. Sexual Dimorphism and Human Psychophysiological Evolution. Moscow: MSU Publ.; 2001. (In Russian)

17.Krane V. We can be athletic and feminine, but do we want to? Challenging hegemonic femininity in women's sport. Quest, 2001; 53(1): 115-133. https://doi.org/10.1080/00336297.2001.10491733

18. Kalinina NA. Hyperandrogenic Disorders of Reproductive System Among Sportswomen. [dissertation]. Moscow; 2004. (In Russian)

19.Moir A. Brain Sex: the Difference Between Men and Woman. Jessel: Indiana University; 2003.

20.Nikityuk BA. The condition of a female organism's specific functions by going in for sport. Teoriya i Praktika Fizicheskoy Kultury, 1984; 3: 19-21. (in Russian)

21.Vrublevskiy EP, Kostyuchenko VF. Morphofunctional aspects of the selection and training of athletes in speedstrength types of athletics. Scientific notes of the University. P.F. Lesgaft. 2009; 4: 33-38. (in Russian)

22.Shakhlina LA-G, Chistyakova MA. Gender politics and issues of sexual dimorphism in the practice of modern sports. Sports medicine and physical rehabilitation, 2019; 2: 18-23. https://doi.org/10.1016/j.asmart.2019.10.001

23.Kagan VE. Violation of gender identity. Handbook of Psychology and Psychiatry of childhood and adolescence. St. Petersburg: Piter; 2000. (in Russian)

24. Mitchell JE, Baker LA, Jacklin CN. Masculinity and Femininity in Twin Children: Genetic and Environmental Factors. Child Development, 1989;60:1475. https://doi.org/10.2307/1130936

25.PowellGN.Onemoretime:Dofemaleandmalemanagersdiffer? Academy of Management Perspectives, 1990; 4(3): 68-75. https://doi.org/10.5465/ame.1990.4274684

26.Royce WS, Gebelt JL, Duff, RW. Female athletes: Being both athletic and feminine. Athletic Insight: The Online Journal of Sport Psychology, 2003; 5(1): 47-61.

27.Tarasevich E, Mulik V, Grashchenkova Zh, Okun D. Gender similarities and gender differences of athletes and sportswomen in cyclic sports, Slobozhansky scientific and sports bulletin, 2020; 2(76): 73-90. (in Ukrainian) https://doi.org/10.15391/snsv.2020-2.005

28.Burn S. The social psychology of Gender. Mc Craw Hill, Inc.; 2000.

29.Manning JT, Scutt D. Wilson J, Lewis-Jones DI. The ratio of 2nd and 4th digit length: a predictor of sperm numbers and concentrations of testosterone luteinizing hormone and oestrogen. Human Reproduction, 1998; 13(11): 3000-3004. https://doi.org/10.1093/humrep/13.11.3000

30.Manning JT, Bundred PE. The ratio of 2 nd to 4 th digit length: a new predictor of disease predisposition? Medical hypotheses, 2000; 54(5): 855-857. https://doi.org/10.1054/mehy.1999.1150

31.Hönekopp J, Manning JT, Müller C. Digit ratio (2D: 4D) and physical fitness in males and females: Evidence for effects of prenatal androgens on sexually selected traits. Hormones and Behavior, 2006; 49(4): 545-549. https://doi.org/10.1016/j.yhbeh.2005.11.006

32.Neyse L, Brañas-Garza P. Digit ratio measurement guide. Kiel working papers, 2014; 1914: 1-11. https://doi.org//hdl.handle.net/10419/96132

33. Oyeyemi BF, Iyiola OA, Oyeyemi AW, Oricha KA, Anifowoshe AT. Alamukii NA. Sexual dimorphism in ratio of second and fourth digits and its relationship with metabolic syndrome indices and cardiovascular risk factors. Journal of research in medical sciences, 2014; 19(3): 234-239.

34.Williams TJ, Pepitone ME, Christensen SE, Cooke $\mathrm{BM}$, Huberman $\mathrm{AD}$, Breedlove NJ, et al. Finger-length ratios and sexual orientation. Nature, 2000;404:455-6. https://doi.org/10.1038/35006555

35.Babichev VN. Neuroendocrinology of the sex. Moscow: Science; 1981. (in Russian)

36.Bem SL. Theory and measurement of androgyny. Journal of Personal and Social Psychology, 1979; 37: 1047-1054. https://doi.org/10.1037/0022-3514.37.6.1047

37.Vrublevskiy EP, Sevdalev SV, Narskin AG, Kozhedub MS. Technology of individualization training of qualified athletes: theoretical and methodological aspects. Gomel: F.Skoruna GSU; 2016. (in Russian)

38.Semenov VG, Vrublevskiy EP. Patterns of adaptive variability in the strength of the muscles of female sprinters in the process of the development of sportsmanship. Teoriya 
i Praktika Fizicheskoy Kultury, 2000; 9: 22-24. (in Russian)

39.Kelly GF. Fundamentals of modern sexology. St. Petersburg: Piter; 2000. (in Russian)

40.Viru AA, Kirge PK. Hormones and athletic performance. Moscow: Physical education and sport; 1983. (in Russian)

41.Sutton JR., Coleman MJ, Casey J, Lazarus L. Androgen Responses during Physical Exercise. British Medical Journal, 1973; 1(5852): 520-522. https://doi.org/10.1136/bmj.1.5852.520

42.Selye G. At the level of the whole organism. Moscow: World; 1982. (in Russian)

43.Butovskaya ML. Secrets of gender. The man and the woman in the mirror of evolution. Fryazino: Vek-2; 2004. (in Russian)

44.Barbieri SRL. Hyperandrogenic disorders. Obstetrics \& Gynecology, 1990; 33: 640-650. https://doi.org/10.1097/00003081-199009000-00028

45.Akyol P, Tutkun E, Cebi M. The influence of hand finger length ratio on the motoric and functional dominance of women dancers, athletes and sedentaries. International Journal Of Academic Research, 2016; 8(3): 43-51 https:// doi.org/10.7813/2075-4124.2016/8-3/B.6

46. Chernyshova FA, Kiamova NI, Islamova NM. Finger index of athletes of different levels of sports training. In the world of scientific discovery, 2015; 10.1(7): 360-375. (in Russian)

47.Abramova TF. Finger dermatoglyphics and physical abilities. [dissertation]. Moscow; 2003. (in Russian)

48.Bescos R. Esteve M, Porta J, Mateu M, Irurtia A, Voracek, M. Prenatal programming of sporting success: Associations of digit ratio (2D:4D), a putative marker of prenatal androgen action, with world rankings in female fencers. Journal of Sports Science. 2009; 27 (6): 625-632. https://doi.org/10.1080/02640410802707029

49. Oladipo GS, Anugweje KC, Jervas K, Amasiatu VC, Ipigansi UN, Enefe G. Second digit length, fourth digit length and second to fourth digit ratio (2D: 4D): Relevance in the choice of female footballer athletes and female non-footballer athletes in Nigeria. Anthropology, 2017; 2(1): 23-28. https://doi.org/10.17140/ANTPOJ-2-109

50.Tambe MK, Turankar AV, Lingawar S, Dhokane NB, Pophali NP, Kherde PM, Bajaj V. Influence of digit ratio (2D: 4D) on reaction time and athletic sprint performance: A short term pilot study. MedPulse International Journal of Physiology, 2018; 5(2): 17-21. https://doi.org/10.26611/103523

51.Acar H, Eler N. The relationship of digit ratio (2D: 4D) with cerebral lateralization and grip strength in elite swimmers. Journal of education and training studies, 2018; 6(4): 84-89. https://doi.org/10.11114/jets.v6i4.3040

52.Paul SN, Kato BS, Hunkin JL, Vivekanandan S, Spector TD. The big finger: the second to fourth digit ratio is a predictor of sporting ability in women. British journal of sports medicine, 2006; 40(12): 981-983. https://doi.org/10.1136/bjsm.2006.027193

53.Kamińska E, Szymańska-Parkieta K. Formaty palcowe $u$ kandydatów $i$ kandydatek do szkoty sportowej [Finger formats for candidates for sports schools]. Katowice: AWF; 2003: 350-354. (in Polish)

54.Wunder PA. Endocrinology of the sex. Moscow: Medicine; 1980. (in Russian)

55.Rosenfield RL. Hyperandrogenism in peripubertal girls. Pediatric Clinics of North America, 1990; 37(6): 1333-1358. https://doi.org/10.1016/S0031-3955(16)37014-6

56.Klorin AI, Chtetsov VP. Biological problems of the doctrine of man's constitution. Leningrad: Science; 1979. (in Russian)

57.Geodakyan VA. The theory of gender differentiation in human problems. Moscow: Science; 1989. (in Russian)

58.Medvedev V. Hormones play. SPEED-INFO, 2004; 20: 26. (in Russian)

\section{Information about the authors:}

Eugeny P. Vrublevskiy; (Corresponding Author); Doctor of Pedagogical Sciences, prof.; https://orcid.org/0000-0001-50537090; vru-evg@yandex.ru; Francisk Skorina Gomel State University; Sovetskaya Street, 104, Gomel, 246000, Belarus. University of Zielona Góra; Licealna Street, 9, Zielona Góra, 65-417, Poland.

Anatoly D. Skrypko; Doctor of Pedagogical Sciences, prof.; https://orcid.org/0000-0002-6472-6535; anskrypko@wp.pl; State University of Applied Sciences in Kalisz; Kaszubska Street 13, Kalisz 62-800, Poland.

Ryszard Asienkiewicz; Doctor of Biological Sciences, prof.; https://orcid.org/0000-0002-6613-818X; ryszard.asienkiewicz@ interia.pl; University of Zielona Góra; Licealna Street, 9, Zielona Góra, 65-417, Poland.

\section{Cite this article as:}

Vrublevskiy EP, Skrypko AD, Asienkiewicz R. Individualization of selection and training of female athletes in speed-power athletics from the perspective of gender identity. Physical Education of Students, 2020;24(4):227-234.

https://doi.org/10.15561/20755279.2020.0405

This is an Open Access article distributed under the terms of the Creative Commons Attribution License, which permits unrestricted use, distribution, and reproduction in any medium, provided the original work is properly cited http://creativecommons.org/licenses/by/4.0/deed.en

Received: 03.05.2020

Accepted: 15.06.2020; Published: 30.08 .2020 